\title{
TEACHING AND LEARNING DESIGN IN A CERAMICS PROJECT - SHARING KNOWLEDGE BY PRACTICE
}

\author{
Cristina SALVADOR \\ CIAUD, Lisbon's School of Architecture, Universidade de Lisboa
}

\begin{abstract}
A PhD grant for a research on children's furniture brought the opportunity of teaching in the design degree of Lisbon's School of Architecture of the University of Lisbon. On the $2^{\text {nd }}$ year, in particular, the students got in touch with designing ceramics, learning its methods and technologies, in a hands-on and very practical stage of the degree. This paper reports a teaching/learning process in which a childfriendly tile project in ceramics was developed and put to practice, working side-by-side with the students, monitoring them, prototyping ceramic coatings and other objects, while giving them the opportunity to follow the tile project and share their own experience and practical understanding of the material's potentiality. It was observed that this process allowed an enriched interaction between teacher and students, in which both subjects teach and learn, sharing knowledge and experience. Strengthening ties with motivation and enthusiasm, while watching the projects grow and develop, within a context of an applied practical knowledge in the academy, also establishing bridges with an industrial professional practice. A study based in questioning was made with university students, female and male, searching for their reactions at a hands-on design teacher who is also a student, their reactions to projects by teachers connecting the academy with professional practice and the impact of the interaction on their projects and motivation to pursue the design degree. Although with small sample limitations, the study found positive results, which may reflect the importance of design practice and experience sharing in the teaching and learning process.
\end{abstract}

Keywords: Product design, design for children, ceramics, design practice, design teaching

\section{INTRODUCTION}

With a background of professional practice in industrial and interior design, a $\mathrm{PhD}$ research on product design was developed, focusing on children's furniture and its adaptation to the child and sustainability. The research project focused on high chairs for children from 6 months up to 7 years of age and it is based on practical experience derived from theoretical and empirical studies, resulting in the development of a children's furniture design project, fully prototyped and evaluated by children, parents and specialists.

This research was awarded with a $\mathrm{PhD}$ grant, which gave the opportunity of an ongoing experience in teaching on the design degree of Lisbon's School of Architecture of the University of Lisbon. The design degree is organised in 6 semesters ( 3 years) and its nuclear discipline is design project, which is mainly focused in product design. In this discipline, on the $1^{\text {st }}$ semester of the $2^{\text {nd }}$ year, it is proposed to the students to design products in ceramics, learning its methods and technologies but also its limitations and advantages, in a hands-on and very practical stage of the design degree. The concept of learning applied to practice, which was essential in the children's furniture research project's overall learning experience by the author, emerged as an opportunity of appliance also to teaching. The need for practicing the knowledge in ceramics was felt, also to be able to set an example to the students, enhancing team work, accepting contributions from their experience and be more connected with them, in a shared experience in learning.

By the old paradigm of Instructionism, educational practices were teacher focused, skill-based, productoriented and non-interactive [1]. With a multidisciplinary nature, product design's education is currently linked to knowledge transfer by practical experience [2], as several thinkers related to Constructivist theories, considered learning to be a construction of exploration and experience [3] [4] [5] in a nonlinear process. In a student-centred classroom the roles of teacher and student change, so that the teacher 
changes from the "sage on the stage" to the "guide on the side" [6] [7], so students are not empty recipients to fill with knowledge but researchers to be guided along their intellectual developmental journey [7]. When a teacher is also a student and a professional industrial designer, the roles may shift. When developing projects side-by-side with the students, the teacher is able to give a practical professional example to the students as if they are in a design studio environment. They may actually relate more with the teacher as a learner/researcher and feel more engaged in the teaching/learning process as all subjects may learn by practice at the same time and also with each other's background and experience.

During the classes, a teaching/learning process was put to practice by the author as a teacher/student and a designer, in which a child-friendly tile's project in ceramics was developed. Working on this project, side-by-side with the students, the aim was to monitor them in the development of the proposed exercises, prototyping several hand scale objects in ceramics, while giving them the opportunity to follow the child-friendly tile's project and share their own experience and practical understanding of the material's potentiality.

In order to evaluate the shared experience, it was necessary to conduct a study by questioning, searching for information about the students' reactions to the teaching/learning process in which they were involved. So that it is possible to attain more information about the relevance of this experience in the context of knowledge transfer by shared practice in design education.

\section{TEACHING/LEARNING PROCESS}

The students were able to develop their projects for the proposed exercises in the semester (un-electrified sound amplifiers in design project discipline and tiles in technologies discipline) in the ceramics workshop (Fig. 1), whilst following the development of the child-friendly tile's project. This project intends to stimulate the interaction of the child with the surroundings and it was created, developed and prototyped using a manufactured plaster cast and liquid white clay, fired and white glazed in oven. Observation was the research method applied during the process, often with the help of photographic recording media.
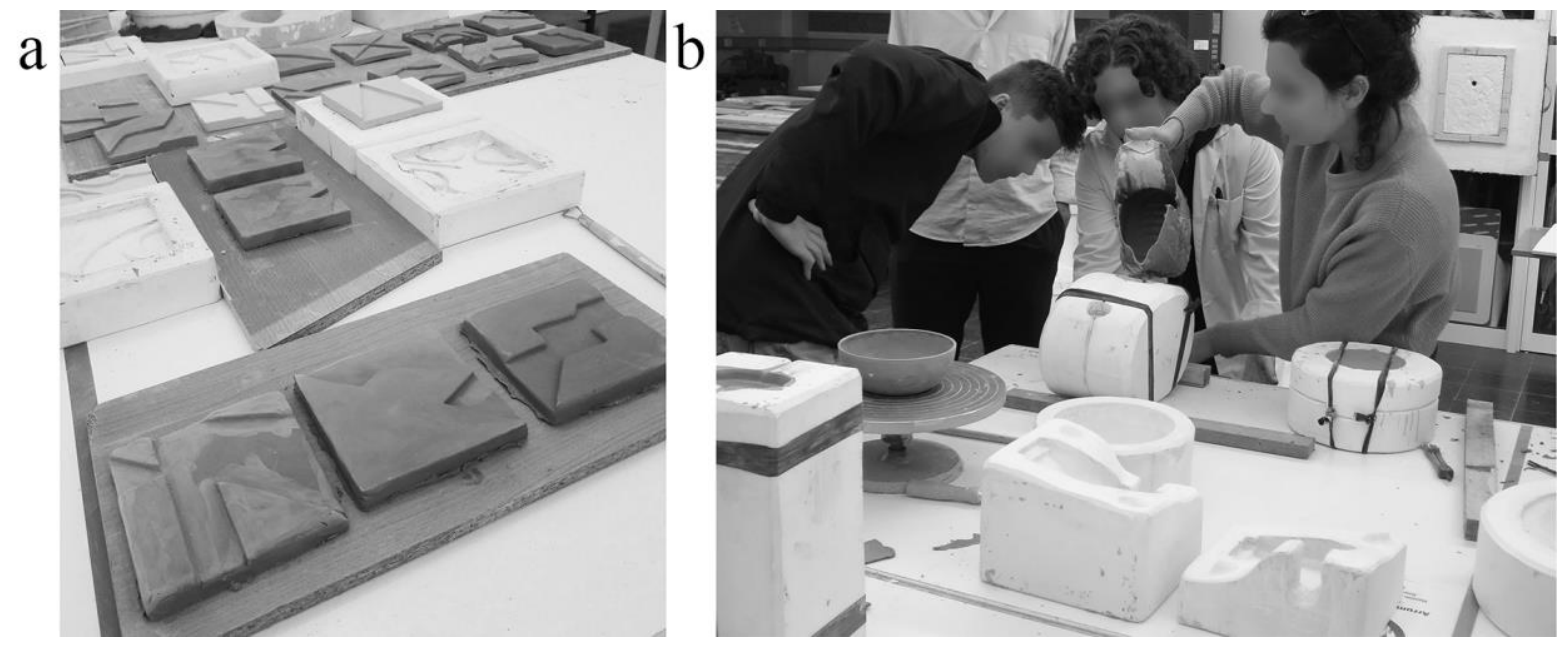

Figure 1. a. Tiles made with plaster casts by the students; $b$. Students and teacher (safeguarded identities) during the classes, working in the workshop - filling plaster casts with liquid white clay, photos: Cristina Salvador, Miguel Aboim, Portugal

A lot of motivation and enthusiasm was felt, while watching the projects grow and develop, within the context of an applied practical knowledge in the academy. Being able to also establish connections with an industrial professional practice, each student succeeded in achieving fully functional prototypes, but bearing in mind that to learn how to lead the process was far more important that having a quickly finished product. The example of the teacher, whose first piece or prototype broke, may have been relevant in their learning experience, as they could see later on, with persistence and more work, never giving up, the positive results would come. They could look at failure, as a part of the process of growing and becoming a designer, overcoming problems and limitations, to succeed. 
In the child-friendly tile's project, the students shared their experience, asked questions and gave contributions to the design process. At the workshop, students felt more at ease to have personal conversations with the teacher. The distance between teacher and student felt more narrowed, enabling more emotional connection, empathy and trust, without loss of respect.

It was considered by the author that this teaching/learning process allowed a more enriched interaction between teacher and students, in which both subjects teach and learn, sharing knowledge and experience.

\section{THE STUDY}

\subsection{Method and Aim}

The study was conducted with 19 university students (19-24 years of age). It was firstly defined as a mainly qualitative interview based study, but in order to give the students more privacy in answering, a one page printed questionnaire, which they could answer anonymously, was distributed to the students (female and male) from a $2^{\text {nd }}$ year class (pre-existing group) in the product design discipline from the design degree in Lisbon's School of Architecture from the University of Lisbon, Portugal. To extract quantitative data with some detail of opinion, in order to be more comprehensive and statistically analysed, the option was to use a five-point Likert [8] graphic scale, ranging from "none" to "very much" for the 6 questions proposed (Table 1). Primal to the questions, data regarding age and gender was asked. The aim of this study was to search for information on:

- $\quad$ Reactions to a teacher-student: sharing knowledge and experience, monitoring and proximity;

- Reactions to projects by teachers: promoting connections with professional practice and industry;

- Positive impact on their projects and motivation to pursue the Design degree.

Table 1. Personal data and questions asked.

\begin{tabular}{|l|}
\hline Age: \\
\hline Gender: \\
\hline 1. Do you consider positive the fact that your teacher has developed a ceramics project \\
while teaching, side by side with the students? \\
(graphic scale - none, not much, neutral, yes, very much) \\
\hline 2. Did you feel there was more sharing of knowledge and experience? \\
(graphic scale - none, not much, neutral, yes, very much) \\
\hline $\begin{array}{l}\text { 3. Did you feel there was more monitoring and proximity? } \\
\text { (graphic scale - none, not much, neutral, yes, very much) }\end{array}$ \\
\hline 4. Is it motivating for you to be able to follow projects that the teachers may develop at \\
school as designers, promoting connections to a professional practice and industry? \\
(graphic scale - none, not much, neutral, yes, very much) \\
\hline $\begin{array}{l}\text { 5. Do you think this experience in learning had positive impact in your own project? } \\
\text { (graphic scale - none, not much, neutral, yes, very much) }\end{array}$ \\
\hline $\begin{array}{l}\text { 6. This semester, characterised by a shared experience in learning about ceramics } \\
\text { with a teacher who's also a student and a designer, contributed to motivate you to pursue } \\
\text { the Design degree? } \\
\text { (graphic scale - none, not much, neutral, yes, very much) }\end{array}$ \\
\hline
\end{tabular}

\subsection{Results}

The results of the questionnaire were analysed and graphically represented, according to percentages rounded to the nearest tenth (Fig. 2). The sample was overwhelmingly female (78.9\%) with only $10.5 \%$ of male gender. There was a similar percentage of the sample that didn't answer. There were $26.3 \%$ of students who were 19 years old, $47.4 \%$ of students who were 20 years old, $10.5 \%$ of students who were 21 years old, $5.3 \%$ of students who were 24 years old and $10.5 \%$ of the students didn't answer.

The results for the first question were overwhelmingly positive, with only one neutral answer (5.3\%). The question searched for the students' reactions to a teacher developing a ceramics project while teaching, side by side with the students and asked whether they found it positive. So, $47.4 \%$ of the students stated it was very positive and the same percentage considered it positive.

The second question searched for consequences of the teaching/learning experience and on whether they felt there has been more sharing of knowledge and experience. The results are also mainly positive, despite $21.1 \%$ of neutral answers and 5.3\% of negative answers ("not much"), $21.1 \%$ answered "very much" and 52.6\% answered "yes". 

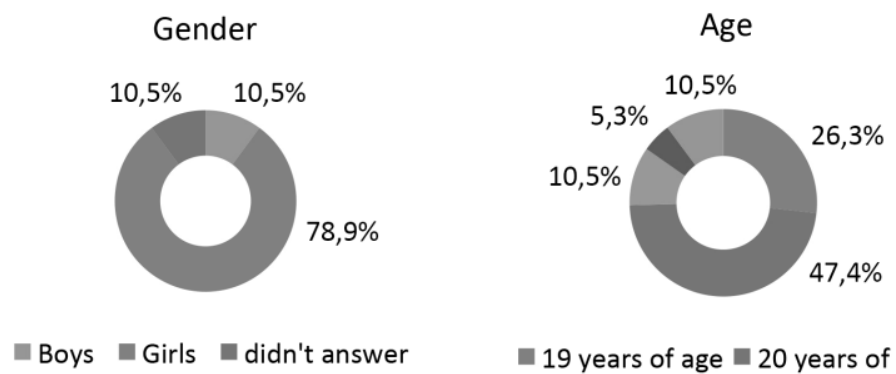

19 years of age 20 years of age

21 years of age $\square 24$ years of age

didn't answer

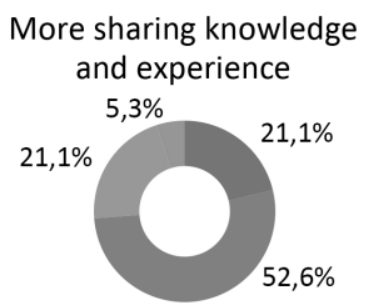

very much 1 Yes

Neutral Not much

\section{More monitoring and proximity}

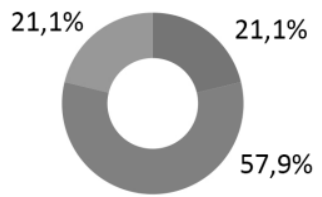

Very much Yes Neutral
Teacher developing project

whilst teaching is positive

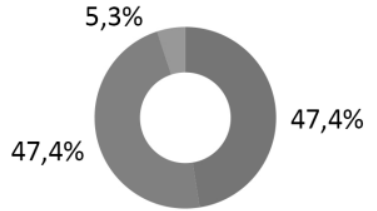

Very much Yes Neutral
Connections with professional practice and industry are motivational

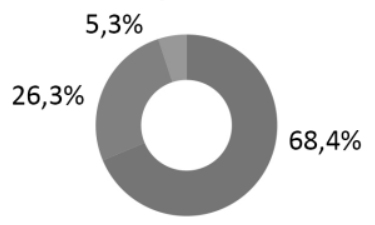

Very much $\quad$ Yes Neutral
Learning experience positively affected your projects

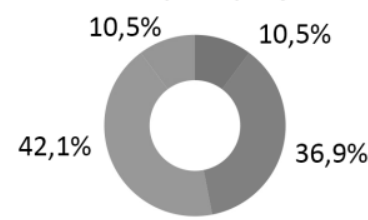

- Very much 1 Yes

Neutral Not much
Contributed to motivate you to pursue Design course

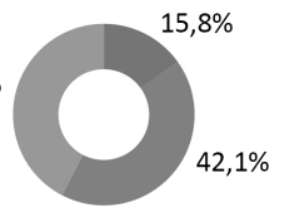

Very much Yes Neutral

Figure 2. Graphics with the results of the study with university students - Product Design discipline from the $1^{\text {st }}$ semester / $2^{\text {nd }}$ year of the Design degree, Lisbon's School of Architecture, University of Lisbon, Portugal, digital illustration: Cristina Salvador, Portugal

The third question searches on whether there was more monitoring and proximity as consequences of the experience and once again the results are mainly positive. $21.1 \%$ of the sample considered there was much more monitoring and proximity, $57.9 \%$ answered "yes" and only $12.1 \%$ had a neutral answer.

As for the fourth question, the majority (68.4\%) considered that following projects eventually developed by teachers as designers, promoting connections to professional practice and industry is very motivating and $26.3 \%$ considered to be motivating. With only one $(5.3 \%)$ neutral answer and the highest percentage for "very much" answers, these were the most positive results from the study.

In the fifth question the aim was to search for direct benefits from the teaching/learning experience in the students' own projects. Although with $10.5 \%$ negative answers ("not much"), the opinions were 
mostly divided between positive (10.5\% "very much" and 36.9\% "yes") and neutral answers (42.1\%). It seemed the students acknowledged the teaching/learning experience being mostly positive or even very positive by the results of the previous questions, but more than half of them doesn't seem to recognise the benefits from it, on their work.

As for the sixth and final question, it was asked if the semester, which was characterised by a shared experience in learning about ceramics with the teacher/student/designer, has contributed to motivate the students to pursue the Design degree. The results are slightly more positive than the results from the previous question: there is no percentage of negative answers; both percentages of positive and very positive answers are strengthened (42.1\% "yes" and $15.8 \%$ "very much"); and neutral answers maintain $42.1 \%$. Still neutral answers' percentage continues to be much higher than in the previous questions.

\section{DISCUSSION}

Student-centred classrooms are believed by many scholars to provide a more effective learning environment [7]. In such context, an experience consisting in a teaching/learning mixed process was conducted during classes in the $1^{\text {st }}$ semester of the $2^{\text {nd }}$ year of the design degree in Lisbon's School of Architecture, University of Lisbon, Portugal.

In this process, a child-friendly tile's project in ceramics was developed by the teacher and put to practice, working side-by-side with the students, monitoring them in their tasks while developing and prototyping hand scale ceramic objects, giving them the opportunity to follow the tile's project and share their own experience.

The author considered it to be a positive experience, allowing a more enriched interaction between teacher and students, in which both subjects teach and learn, sharing knowledge and experience. But the process needed evaluation by the students involved. In order to attain more information about the relevance of this experience in the context of knowledge transfer by shared practice in design education, a study by questioning was conducted with 19 university students aged 19-24 years, female and male. The overwhelming percentage of female students in the design degree has been a growing tendency, becoming the new paradigm in the last few years. The vast majority was between 19 and 20 years of age. As Piaget defined, in terms of cognitive development, these students who are in a late teenage phase leading to adulthood, are in a formal operational stage [9]. They are able to think logically in the abstract and can see the relationships between things. They can think creatively, using abstract reasoning and imagine the outcome of particular actions [9]. Design students are particularly asked to practice this kind of skills, as problem solving is central in this multidisciplinary activity. Curiosity is quite important in this setting, in order to guarantee full engagement from the student on the learning process during a design project.

The first question searched for the students' reactions to a teacher developing a ceramics project while teaching, side-by-side with the students and asked whether they found it positive. The results were overwhelmingly positive. The next two questions searched for consequences of the teaching/learning experience and on whether they felt there has been more sharing of knowledge and experience, more monitoring and proximity. Once again, the results were mainly positive.

The fourth question produced the most positive results from the questionnaire, becoming clear that the majority of the students involved in the experience considered that following projects eventually developed by teachers as designers, promoting connections to professional practice and industry is very motivating for them.

When asked if the students think the learning/teaching experience affected positively their own projects, the clear positive results from previous questions do not replicate. The opinions diverge mostly between positive and neutral answers. More than half of the students didn't seem to recognise the benefits on their work, from the experience, they stated to find positive or even very positive in previous answers.

Finally, it was asked if the semester, characterised by a shared experience in learning ceramics with a teacher/student/designer, has contributed to motivate the students to pursue the design degree and the results are slightly more positive, although maintaining the percentage of neutral answers.

Without trying to overlook the results from the last two questions, which reflected an increase of neutral answers, the general results are still quite positive. Although students mostly found the experience positive or very positive, they have more difficulty in acknowledging it affected positively their performance as design students. 


\section{CONCLUSIONS}

Due to the small extent of the sample, the results of observation and questioning are not sure to generalise to a wider population. If replicated with other classes in the future, it would be possible to achieve a more substantiated evaluation of this experience, with a bigger sample.

Nevertheless, with the amount of positive results found in this study, it may be concluded that the students involved, generally welcomed the teaching/learning experience. They found very positive to have teachers, who are also students and designers, developing projects in school, side-by-side with them, establishing connections with a professional practice in design and sharing knowledge by experience.

Experiences of this nature may result in more enthusiasm and engagement from students and the results may reflect the importance of design practice and experience sharing in the teaching/learning process, bearing in mind the obstacles and demands of a design degree.

\section{ACKNOWLEDGEMENTS}

Without the support of the University of Lisbon, Lisbon's School of Architecture, CIAUD - Research Centre in Architecture, Urbanism and Design and FCT - Foundation for Science and Technology, Portugal, this study wouldn't be possible. Special thanks to the students, who participated in the experience, as well as to the ceramic specialist Isa Sardinha and Profs. Ana Cristina Dias and Miguel Aboim, who supported the study.

\section{REFERENCES}

[1] Johnson G. Instructionism and Constructivism: Reconciling two very good ideas. 2009. International Journal of Special Education, 24(3), 1-25.

[2] Adams R. et al. Being a professional: Three lenses into design thinking, acting, and being, Design Studies Vol. 32, issue 6, 2011. Science Direct, Elsevier.

[3] Dewey J. Democracy and Education, 2004. Dover Publications, Inc., New York.

[4] Kamii C. A teoria de Piaget e a educação préescolar, 2003. Instituto Piaget, Lisboa.

[5] Vygotsky L. Mind in Society, 1978. Harvard University Press, Oxford.

[6] Weimer M. Learner-centred teaching: Five key changes to practice. 2002. Jossey-Bass, San Francisco.

[7] Wright G. Student-Centred Learning in Higher Education. 2011. International Journal of Teaching and Learning in Higher Education, Volume 23, Number 3, 92-97.

[8] Jamieson S. Likert scale. Encyclopaedia Britannica. Available: https://www.britannica.com/topic/Likert-Scale [Accessed on 2019, 08 March]

[9] Inhelder B. and Piaget J. The Growth of Logical Thinking from Childhood to Adolescence. 1958. Basic Books, New York. 